\title{
二元钒嗍化物的反应合成及其放电性能
}

\author{
潘 ${ }^{1}$, 路 新 $^{1}$, 魏治国 ${ }^{1}$, 王国庆 ${ }^{2}$, 曲选辉 ${ }^{1}$
}

(1. 北京科技大学 新材料技术研究院，北京 $100083 ; 2$. 新材料与产业技术北京研究院，北京 102200)

摘 要: 以单质元素粉末为原料，采用 $1500^{\circ} \mathrm{C}$ 高温反应合成不同成分的钒硼化物粉末，并以制备粉末为活性物质， $\mathrm{Ni}$ 为导电剂, $\mathrm{NH}_{4} \mathrm{HCO}_{3}$ 为造孔剂, 采用粉末冶金工艺制备了多孔 $\mathrm{V}-x \mathrm{~B} / \mathrm{Ni}$ 型 $(x=2 / 3 \sim 2)$ 负极电极片, 探讨不同物相钒 嗍化物作为空气电池电极活性物质的高容量输出性能。结果表明，当原料粉末中 $\mathrm{V}: \mathrm{B}$ 原子比为 $1: 1 、 1: 2$ 时，可分别 制得具有单一物相的 $V B$ 和 $V B_{2}$ 化合物粉末，当 $V: B=3: 2$ 时，合成产物包含 $V_{3} B_{2}$ 和少量 $V B$ 相，当 $V: B=2: 3$ 时，合 成产物为 $\mathrm{V}_{2} \mathrm{~B}_{3} 、 \mathrm{~V}_{3} \mathrm{~B}_{4}$ 和少量 $\mathrm{VB}_{2}$ 三相混合。制备的 $\mathrm{V}-x \mathrm{~B} / \mathrm{Ni}$ 型电极的孔隙率为 $60.25 \sim 61.75 \%$, 放电容量为 6129 7901 mAh, 比容量为 2724 3511 mAh/g。 V-xB/Ni 型电极的放电性能随着 $\mathrm{B}$ 含量的增加明显提升, 所制备 $\mathrm{V}-2 \mathrm{~B} / \mathrm{Ni}$ 型电极的放电性能最优, 其比容量为 $3512 \mathrm{mAh} / \mathrm{g}$, 库伦效率为 $86.5 \%$, 能量密度达到 $2504 \mathrm{Wh} / \mathrm{kg}$ 。

关 键 词: 反应合成; 钒嗍化物; 粉末冶金; 空气电池

中图分类号: TQ174 文献标识码: A

\section{Reaction Synthesis and Discharge Performance of Binary Vanadium Borides}

\author{
PAN Yu ${ }^{1}$, LU Xin ${ }^{1}$, WEI Zhi-Guo ${ }^{1}$, WANG Guo-Qing ${ }^{2}$, QU Xuan-Hui ${ }^{1}$
}

(1. Institute for Advanced Materials and Technology, University of Science and Technology Beijing, Beijing 100083, China; 2. Material and Industrial Technology Research Institute Beijing, Beijing 102200, China)

\begin{abstract}
Vanadium boride compound powders with different compositions were prepared by reactive synthesis at $1500^{\circ} \mathrm{C}$ from elemental powders. Then, with the obtained powders as active materials, Ni powder as conductive agent and $\mathrm{NH}_{4} \mathrm{HCO}_{3}$ as space-holder, the porous anodes of $\mathrm{V}-x \mathrm{~B} / \mathrm{Ni}(x=2 / 3 \sim 2)$ were fabricated by powder metallurgy (PM), respectively. The effects of $\mathrm{V}-x \mathrm{~B}$ compounds with different phases on the discharge performance of the assembled air batteries were studied. The results show that the single-phased $\mathrm{VB}_{2}$ powder can be obtained from the raw powder with the atomic ratio of $\mathrm{V}: \mathrm{B}=1: 2$, and so does the $\mathrm{VB}$ powder. As for atomic ratio of $\mathrm{V}: \mathrm{B}=3: 2$, the synthesized powder consists of $V_{3} B_{2}$ and a small amount of $V B$, while the ratio of $V: B=2: 3$ yields the phase composition of $V_{2} B_{3}, V_{3} B_{4}$ and minor $\mathrm{VB}_{2}$. The prepared $\mathrm{V}-x \mathrm{~B} / \mathrm{Ni}$ anodes with porosity of $60.25 \%-61.75 \%$ exhibit good discharge performance, and their capacity can reach the range of $6129-7901 \mathrm{mAh}$ while specific capacity is $2724-3511 \mathrm{mAh} / \mathrm{g}$. With the increase of $\mathrm{B}$ content, the discharge performance of $\mathrm{V}-x \mathrm{~B} / \mathrm{Ni}$ anodes shows a significant improvement. In comparison, the porous $\mathrm{V}-2 \mathrm{~B} / \mathrm{Ni}$ anode possesses the superior discharge properties with discharge capacity of $3512 \mathrm{mAh} / \mathrm{g}$, coulombic efficiency of $86.5 \%$ and specific energy of $2504 \mathrm{Wh} / \mathrm{kg}$.
\end{abstract}

Key words: reactive synthesis; V-xB compounds; powder metallurgy; air battery

随着不可再生能源的逐渐枯竭, 能源问题已经 成为人类所面临的重要问题。而然料电池作为高效、
洁净和安全的新能源技术，已经成为新能源开发领 域的研究热点之一。金属空气电池则充分发挥了燃 
料电池的长处, 其比能量高、结构简单、放电电压 平稳, 是未来很有发展和应用前景的一类新兴绿色 能源 ${ }^{1}{ }^{\circ}$ 。金属空气电池以活泼金属作为阳极, 空气中 的氧气作为阴极, 氧气通过气体扩散电极到达气一 液-固三相界面与金属负极发生反应而放出电能 ${ }^{[2]}$ 。 与现有的铅酸、镍氢和锂离子电池相比, 金属空气 电池可实现更高的能量密度和比容量, 而且安全性 更高 ${ }^{[3-4]}$ 。目前商业中应用最广的锌空气电池, 其能 量密度可以达到 $1756 \mathrm{Wh} / \mathrm{L}$, 是锂离子电池能量密 度的 5 倍多, 更是传统碱性 $\mathrm{Zn}-\mathrm{MnO}_{2}$ 电池的 10 倍 以上 ${ }^{[5-6]}$ 。其中金属硼化物作为负极材料具有超高的 理论放电容量和能量密度, 近年来正在引起人们的 关注。 $\mathrm{VB}_{2}$ 在碱性溶液中可以发生 11 电子氧化反应, 理论放电比容量为 $4060 \mathrm{mAh} / \mathrm{g}^{[7-9]}$, 几乎是锌空气 电池理论放电比容量 $(820 \mathrm{~m} \mathrm{Ah} / \mathrm{g})$ 的 5 倍, 能量密度 为 $32000 \mathrm{Wh} / \mathrm{L}^{[10]}(6270 \mathrm{Wh} / \mathrm{kg})$, 这是目前水溶液体 系金属化合物放电性能的最高水平。

上世纪末, 美国 Steven Amendola 等 ${ }^{[11]}$ 提出了 以硼化物作为电极材料的高能量电池体系。2004 年, 我国杨汉西等 ${ }^{[12]}$ 发现 $\mathrm{TiB}_{2} 、 \mathrm{VB}_{2}$ 等过渡族金属二硼 化物作为空气电池负极材料, 具有超高的电化学容 量。另通过高能球磨法制备了系列 $\operatorname{VB} x(x=0.1 \sim 1)$ 粉末, 并以此为活性物质制备电池负极, 研究表明 引入少量 $\mathrm{B}$ 元素可以显著改善 $\mathrm{V}$ 的阳极活性, $\mathrm{VB} x(x=0.25 \sim 1)$ 的放电比容量可超过 $2000 \mathrm{mAh} / \mathrm{g}^{[13]}$ 。 美国华盛顿大学 Stuart Licht 等 ${ }^{[14]}$ 改善了纽扣式 $\mathrm{VB}_{2}$ 空气负极制备工艺, 使其放电比容量提高至 $3300 \mathrm{mAh} / \mathrm{g}$ 。金属钒嗍化物尤其是 $\mathrm{VB}_{2}$ 作为空气电 池负极材料已被证实具有超常的放电性能, 金属钒 嗍化物体系除 $V_{3}$ 外还包括 $V B 、 V_{3} B_{2} 、 V_{2} B_{3} 、 V_{3} B_{4}$ 等 ${ }^{[15]}$, 但目前将其他物相钒嗍化物作为电极活性物 质的研究还鲜有报道。并且现有过渡族金属嗍化物 空气电池的研究都仅局限于小功率扣式电池, 将其 用于大功率设备及动力电池还尚未见公开报道。

为此, 本工作以单质元素粉末为原料, 采用高 温反应合成工艺制备不同成分配比的 V- $x \mathrm{~B}$ 化合物 粉体, 并以制得的粉体为活性物质, $\mathrm{Ni}$ 粉为导电剂, 采用粉末冶金工艺制备大容量钒嗍化物空气电池用 负极材料, 研究了 $\mathrm{V}-x \mathrm{~B}$ 化合物电极在碱性电解质 溶液中的容量输出性能。

\section{1 实验方法}

\section{1 钒硼化物的反应合成}

将单质 $\mathrm{V}$ 粉 $(<75 \mu \mathrm{m}$, 纯度为 $99 \%)$ 和 $\mathrm{B}$ 粉 $(<45 \mu \mathrm{m}$,
纯度为 $95 \%$ )按照四种原子配比 $\mathrm{V}: \mathrm{B}=3: 2 、 1: 1 、 2: 3$ 、 $1: 2$ 装入混料罐中, 然后放在混料机上混合均匀, 转 速为 $100 \mathrm{r} / \mathrm{min}$, 时间为 $8 \mathrm{~h}$ 。再将均匀混合粉末放入 高纯氩气保护下的管式炉中进行高温处理, 升温速 率为 $5^{\circ} \mathrm{C} / \mathrm{min}$, 烧结温度为 $1500^{\circ} \mathrm{C}$, 保温时间为 $4 \mathrm{~h}$, 随炉冷却后得到四种 $\mathrm{V}-\mathrm{xB}$ 化合物粉末, 最后将粉 末研磨细化。

\section{2 电极片的制备及空气电池的组装}

将制备好的四种 $\mathrm{V}-\mathrm{xB}$ 化合物粉末与 $\mathrm{Ni}$ 粉按质 量比为 $3: 1$ 均匀混合, 加入 $15 \mathrm{wt} \%$ 的 $\mathrm{NH}_{4} \mathrm{HCO}_{3}$ $(180 \sim 250 \mu \mathrm{m})$ 作为造孔剂。将混合粉料在 $\phi 30 \mathrm{~mm}$ 钢 制模具下压制成形，成形压力为 $160 \mathrm{MPa}$ ，保压时 间为 $3 \mathrm{~min}$ 。将成形坏放入管式炉中在高纯氩气保 护下进行烧结, 升温速率为 $5^{\circ} \mathrm{C} / \mathrm{min}$, 烧结温度为 $900^{\circ} \mathrm{C}$, 保温时间为 $2 \mathrm{~h}$, 随炉冷却后制得四种多孔 材料电极片。所制备电极片重量均为 $3 \mathrm{~g}$, 尺寸约为 $\phi 30 \mathrm{~mm} \times 1.85 \mathrm{~mm}$ 。以制得的四种多孔钒嗍化物电 极片为负极, 空气电极为正极组装成硼化钒-空气 电池, 其中空气电极主要由扩散层、集流体和催化 层组成, 催化剂为 $\mathrm{MnO}_{2}$, 面积为 $10 \mathrm{~cm}^{2}$, 电解液为 $6 \mathrm{~mol} / \mathrm{L} \mathrm{KOH}$ 溶液。

\section{3 材料表征}

采用日本理学(Ruguka)公司 Dmax-RB 型 $12 \mathrm{~kW}$ 旋转负极 $X$ 射线分析仪 $(\mathrm{Cu} \mathrm{K} \alpha, \lambda=0.15406 \mathrm{~nm})$ 进行 物相分析。采用 JSM-64810LV 型扫描电镜(SEM)对 材料组织、孔隙形貌、孔径及其分布进行观察。利 用阿基米德排水法测量多孔材料的表观密度 $\rho$ 、总 孔隙率 $P_{\mathrm{t}}$ 及开孔率 $P_{\mathrm{o}}$ 。

对制备电极片进行循环伏安扫描测试，实验采 用三电极体系，工作电极为制备电极片，工作面积 为 $10 \mathrm{~mm} \times 10 \mathrm{~mm}$, 辅助电极为铂电极, 参比电极为 $\mathrm{Hg} / \mathrm{HgO}$ 电极，电解液采用 $6 \mathrm{~mol} / \mathrm{L} \mathrm{KOH}$ 水溶液。选 用上海辰华仪器有限公司生产的 CHI660 型电化学 工作站进行测试, 测试均在室温下进行, 扫描电压 范围为 $-1.2 \sim 0.2 \mathrm{~V}$, 扫描速率为 $0.1 \mathrm{mV} / \mathrm{s}$ 。

组装好的空气电池静置 $10 \mathrm{~min}$ 后进行放电测试, 空气电池正极所用的氧气来自于周围的空气, 所用 仪器为武汉 Land-CT2001 电池测试仪。在 $100 \mathrm{~mA}$ 下恒流放电，截止电压为 $0.3 \mathrm{~V}$ 。

\section{2 结果与讨论}

\section{1 高温合成粉末及其电极的物相分析}

图 1 是高温合成 V-xB 化合物粉体的物相分析 图。对于 $\mathrm{V}: \mathrm{B}$ 原子比为 $1: 1$ 和 $1: 2$ 的原料粉体, 经过 
$1500^{\circ} \mathrm{C}$ 高温处理后得到的粉末分别由 $\mathrm{VB}$ 和 $\mathrm{VB}_{2}$ 单 一物相组成。而当原料粉体中 $\mathrm{V}: \mathrm{B}=3: 2$ 时, 合成产 物中除了 $\mathrm{V}_{3} \mathrm{~B}_{2}$ 相, 还含有少量的 $\mathrm{VB}$ 相。当原料粉 体中 $V: B=2: 3$ 时, 合成产物则包含了 $V_{2} B_{3} 、 V_{3} B_{4}$ 和 少量 $\mathrm{VB}_{2}$ 三种物相。

以合成 $\mathrm{V}-x \mathrm{~B}(x=2 / 3 、 1 、 3 / 2,2)$ 粉末为原料, 添 加 $25 \mathrm{wt} \% \mathrm{Ni}$ 粉, 采用粉末治金造孔剂法在 $900^{\circ} \mathrm{C}$ 低 温烧结制备 $\mathrm{V}-x \mathrm{~B} / \mathrm{Ni}$ 电极片, 其 XRD 图谱如图 2 所 示。实验表明以单质 $\mathrm{Ni}$ 为导电剂, 利用金属 $\mathrm{Ni}$ 的 延展性可以显著提高 $\mathrm{VB}_{2}$ 粉体的压制性以及烧结性 能, 采用模压低温烧结可以制备高强度块体电极 片。当原料中 $\mathrm{B}$ 含量较低 $\mathrm{V}: \mathrm{B}=3: 2$ 时, 制备的 $\mathrm{V}-(2 / 3) \mathrm{B} / \mathrm{Ni}$ 型电极由 $\mathrm{V}_{3} \mathrm{~B}_{2} 、 \mathrm{VB}$ 及 $\mathrm{Ni}$ 三相组成。

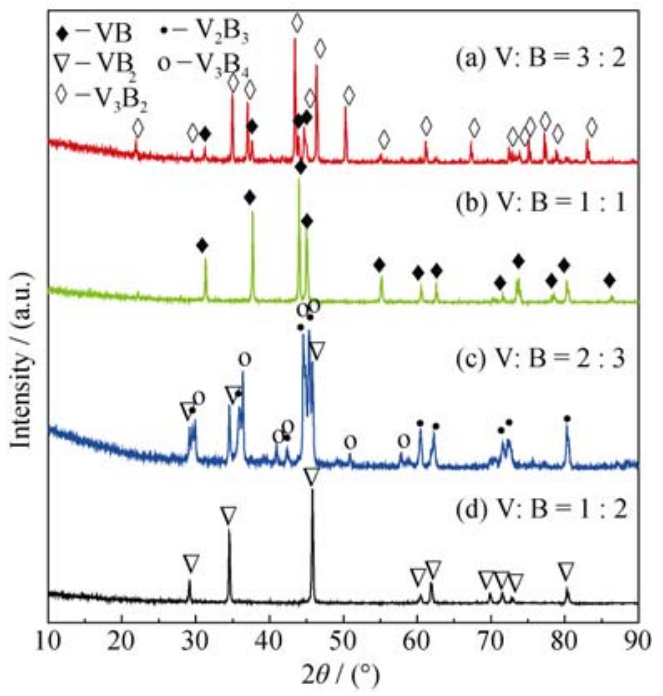

图 1 高温合成 $\mathrm{V}-x \mathrm{~B}$ 化合物粉末的 XRD 图谱

Fig. 1 XRD patterns of $\mathrm{V}-x \mathrm{~B}$ compounds powder by hightemperature synthesis

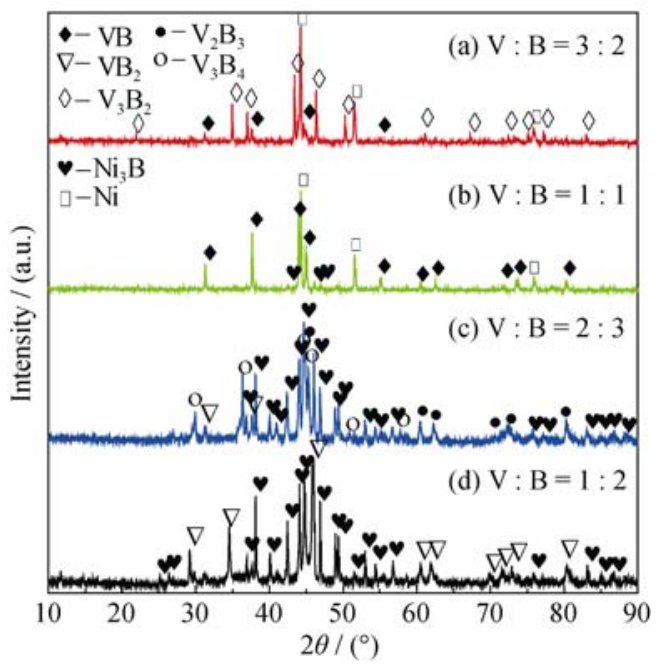

图 2 低温烧结制备 $\mathrm{V}-x \mathrm{~B} / \mathrm{Ni}$ 电极片的 XRD 图谱

Fig. 2 XRD patterns of $\mathrm{V}-x \mathrm{~B} / \mathrm{Ni}$ anodes by low-temperature sintering
当原料中 $\mathrm{B}$ 含量略升高至 $\mathrm{V}: \mathrm{B}=1: 1$ 时，电极中则开 始出现了 $\mathrm{Ni}_{3} \mathrm{~B}$ 新相, $\mathrm{V}-\mathrm{B} / \mathrm{Ni}$ 电极由 $\mathrm{VB} 、 \mathrm{Ni}$ 及少量 $\mathrm{Ni}_{3} \mathrm{~B}$ 组成。进一步提升原料中 $\mathrm{B}$ 含量, 当 $\mathrm{V}: \mathrm{B}$ 原子 比为 $2: 3$ 及 $1: 2$ 时, 单质 $\mathrm{Ni}$ 衍射峰完全消失, $\mathrm{Ni}$ 和 钒硼化物反应完全生成 $\mathrm{Ni}_{3} \mathrm{~B}$ 相, $\mathrm{V}-(2 / 3) \mathrm{B} / \mathrm{Ni}$ 型电极 由 $V_{2} B_{3} 、 V_{3} B_{4} 、 N i_{3} B$ 和少量 $V_{B}$ 相组成, 而 $V-2 B / N i$ 型电极则由 $\mathrm{VB}_{2}$ 及 $\mathrm{Ni}_{3} \mathrm{~B}$ 相组成。

\section{2 电极片的孔隙率分析}

多孔负极片的孔隙率对组装电池的放电性能具 有显著影响, 前期的实验研究结果表明, 添加 $15 \mathrm{wt} \% \mathrm{NH}_{4} \mathrm{HCO}_{3}$ 造孔剂所制备的具有 $60 \%$ 左右的孔 隙率的负极表现出最高的电池容量及库伦效率 ${ }^{[16]}$ 。以 合成的 $\mathrm{V}-x \mathrm{~B}$ 化合物粉末及 $\mathrm{Ni}$ 粉为原料, 所制备的 多孔电极的孔隙率和材料表观密度如图 3 所示。可 以看出，制备的不同成分 V-B 化合物电极的孔隙率 参数接近, 其总孔隙率 $P_{\mathrm{t}}$ 为 $60.25 \% \sim 61.75 \%$, 开孔 率 $P_{0}$ 为 $44.53 \% \sim 49.51 \%$, 材料表观密度 $\rho$ 为 $2.27 \sim$ $2.48 \mathrm{~g} / \mathrm{cm}^{3}$ 。

图 4 为四种电极样品的断面形貌，从断面形貌 图中可以看出, 加入 $15 \mathrm{wt} \% \mathrm{NH}_{4} \mathrm{HCO}_{3}$ 造孔剂后，四 种 $\mathrm{V}-x \mathrm{~B}$ 化合物电极片中含有大量均匀分布的孔洞, 不同成分电极的孔洞形态、分布和尺寸没有明显区 别。其中小尺寸孔径约为 2 4 $\mu \mathrm{m}$, 小孔相互贯通相 连形成大孔, 尺寸约为 50 80 $\mu \mathrm{m}$ 。

\section{3 循环伏安测试}

图 5 为四种 $\mathrm{V}-x \mathrm{~B} / \mathrm{Ni}$ 电极片在 $6 \mathrm{~mol} / \mathrm{L} \mathrm{KOH}$ 溶 液中的循环伏安扫描曲线, 可以看出四种电极 $\mathrm{CV}$ 曲线相近, 且都表现出很强的阳极氧化峰, 表明四 种 $\mathrm{V}-x \mathrm{~B}$ 化合物电极均具有很强的电化学氧化活性。 在相同测试条件下，通过 CV 曲线积分面积可以定 量比较材料的电化学容量 ${ }^{[12]}$ 。根据图 5 的 $\mathrm{CV}$ 曲线

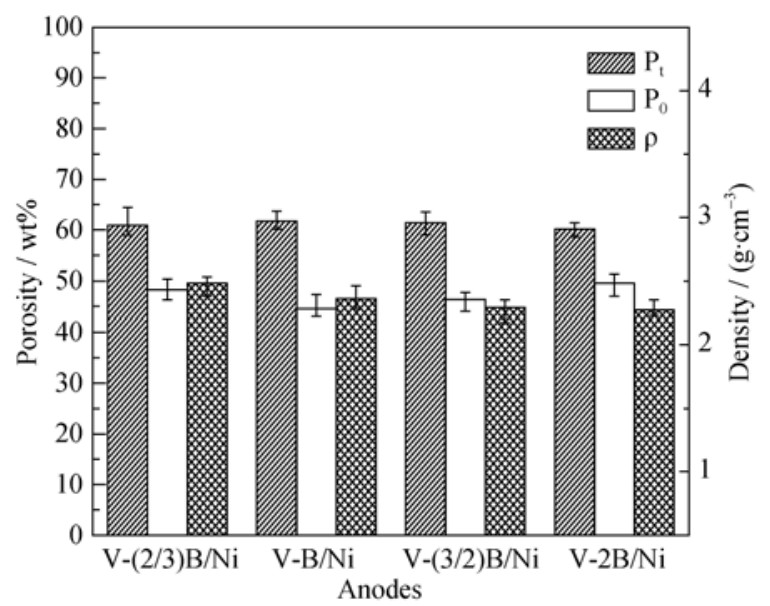

图 3 烧结制备 $\mathrm{V}-x \mathrm{~B} / \mathrm{Ni}$ 型电极片的密度及孔隙度

Fig. 3 Porosity and density of different V- $x \mathrm{~B} / \mathrm{Ni}$ anodes 


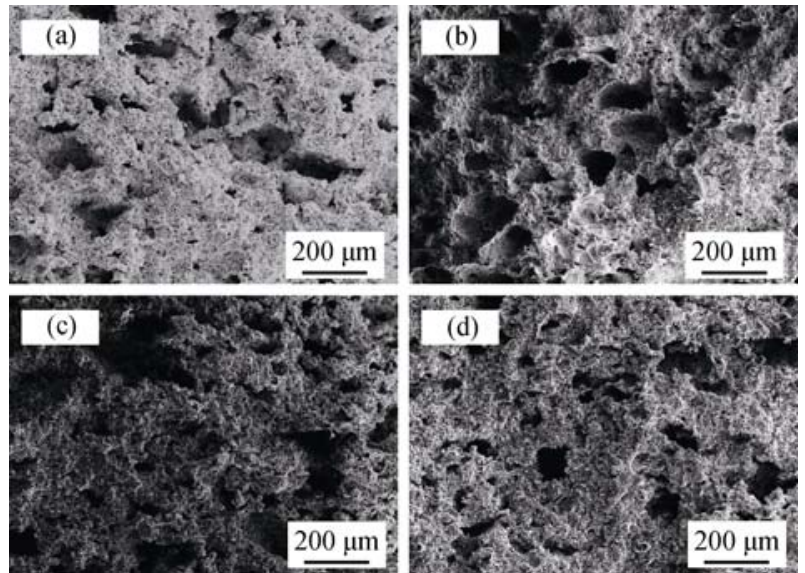

图 4 不同成分多孔 $\mathrm{V}-x \mathrm{~B} / \mathrm{Ni}$ 多孔电极片的断面 SEM 形貌 Fig. 4 SEM images of porous $\mathrm{V}-x \mathrm{~B} / \mathrm{Ni}$ anodes (a) $\mathrm{V}-(2 / 3) \mathrm{B} / \mathrm{Ni}$; (b) $\mathrm{V}-\mathrm{B} / \mathrm{Ni}$; (c) $\mathrm{V}-(3 / 2) \mathrm{B} / \mathrm{Ni}$; (d) $\mathrm{V}-2 \mathrm{~B} / \mathrm{Ni}$

峰面积可以得出 $\mathrm{V}-2 \mathrm{~B} / \mathrm{Ni}$ 的积分面积最大, 表明其 电化学容量最高。而 $\mathrm{V}-(2 / 3) \mathrm{B} / \mathrm{Ni}$ 及 $\mathrm{V}-\mathrm{B} / \mathrm{Ni}$ 和 $\mathrm{V}-3 / 2 \mathrm{~B} / \mathrm{Ni}$ 分别为 $\mathrm{V}-2 \mathrm{~B} / \mathrm{Ni}$ 积分面积的 $84 \% 、 88 \%$ 和 $92 \%$ 。制备 V-2B/Ni 型电池活性物质的理论放电比 容量以 $4060 \mathrm{mAh} / \mathrm{g}$ 计算, 因此根据积分面积可得到 $\mathrm{V}-\mathrm{B} / \mathrm{Ni}$ 型电极所含活性物质理论放电比容量约为 $3573 \mathrm{mAh} / \mathrm{g}$, 而 $\mathrm{V}-2 / 3 \mathrm{~B} / \mathrm{Ni}$ 电极与 $\mathrm{V}-3 / 2 \mathrm{~B} / \mathrm{Ni}$ 电极活 性物质的理论放电比容量则分别为 3410 、 $3735 \mathrm{mAh} / \mathrm{g}$ 。据研究报道, VB 的理论放电比容量为 $3470 \mathrm{mAh} / \mathrm{g}^{[13]}$, 本研究的计算结果与之接近, 表明 采用 $\mathrm{CV}$ 曲线计算制备电极的理论比容量较为准确 可靠。

\section{4 电池的放电性能分析}

采用恒流放电测试四种 $\mathrm{V}-x \mathrm{~B} / \mathrm{Ni}$ 型电极在空气 电池中的放电曲线，可以对比质量和尺寸规则相同， 而成分配比不同的电极片的容量输出性能。图 6 为 四种电极在 $6 \mathrm{~mol} / \mathrm{L} \mathrm{KOH}$ 水溶液中的 $100 \mathrm{~mA}$ 恒流

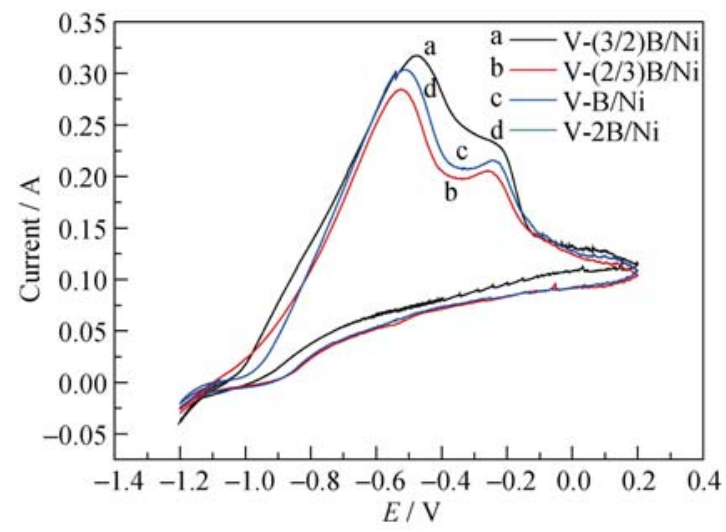

图 $5 \mathrm{~V}-x \mathrm{~B} / \mathrm{Ni}$ 电极片在 $6 \mathrm{~mol} / \mathrm{L} \mathrm{KOH}$ 溶液中的 $\mathrm{CV}$ 曲线

Fig. 5 Cyclic voltammograms of $\mathrm{V}-x \mathrm{~B} / \mathrm{Ni}$ anodes in $6 \mathrm{~mol} / \mathrm{L}$ $\mathrm{KOH}$ solution
放电曲线。表 1 分别列出了电极的平均放电电压、放 电容量、放电比容量、库伦效率和放电比能量, 可以 看出，采用粉末冶金制备工艺制备的 $\mathrm{V}-x \mathrm{~B} / \mathrm{Ni}$ 型电极 具有高容量的放电特征，其放电容量可以达到 6129 $7901 \mathrm{mAh}$, 对应的放电比容量为 $2724 \sim 3511 \mathrm{mAh} / \mathrm{g}$, 是锌空气电池放电理论比容量的 4 倍左右, 库伦效 率达到 $78 \%$ 以上，高于目前报道的扣式 $\mathrm{VB}_{2}$-空气电 池水平 $(75 \%)^{[17-18]}$ 。结果表明以高温反应合成的 $\mathrm{V}-\mathrm{x} \mathrm{B}$ 化合物粉末为原料, 采用粉末冶金方法所制备 的空气电池用负极具有较高的放电性能，可同时实 现高放电容量及活性物质利用率。

四种成分 $\mathrm{V}-x \mathrm{~B} / \mathrm{Ni}$ 型电极放电曲线相似，其平 均放电电压略有区别, 其中 $\mathrm{V}-2 \mathrm{~B} / \mathrm{Ni}$ 电极的放电平 均电压最高, 为 $0.72 \mathrm{~V}$, 而 $\mathrm{V}-\mathrm{B} / \mathrm{Ni}$ 电极电压最低, 为 $0.63 \mathrm{~V}$ 。不同成分配比的电极放电容量随 $\mathrm{B}$ 含量 的增加而提升, $\mathrm{V}-2 / 3 \mathrm{~B} / \mathrm{Ni}$ 与 $\mathrm{V}-\mathrm{B} / \mathrm{Ni}$ 电极的容量较 低, 分别为 $2724 \mathrm{mAh} / \mathrm{g}$ 和 $2796 \mathrm{mAh} / \mathrm{g}$, 而 $\mathrm{V}-2 \mathrm{~B} / \mathrm{Ni}$ 电极的容量显著提升, 达到 $3512 \mathrm{mAh} / \mathrm{g}$, 其库伦效 率为 $86.5 \%$, 能量密度达到 $2504 \mathrm{Wh} / \mathrm{kg}$, 表明所制 备的 $\mathrm{V}-2 \mathrm{~B} / \mathrm{Ni}$ 电极具有最优的放电输出性能。

四种成分电极放电之后外形保持完整，相对于 放电前表面更为疏松，其强度明显降低。放电后电
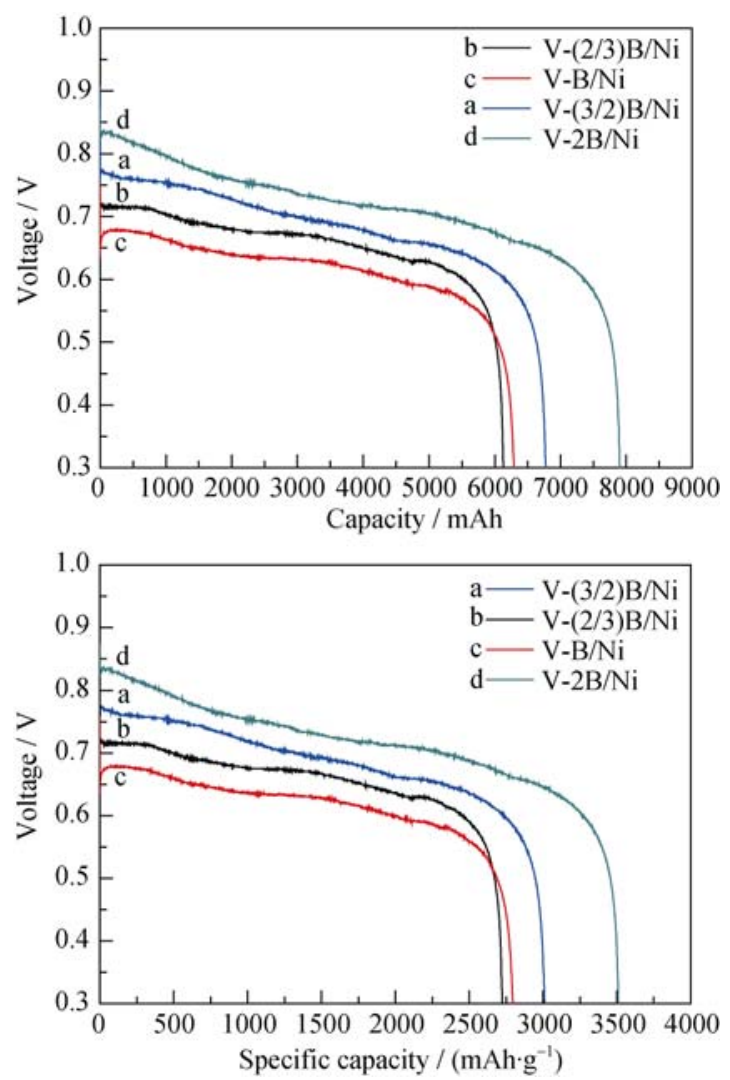

图 $6 \mathrm{~V}-x \mathrm{~B} / \mathrm{Ni}$ 电极在 $6 \mathrm{~mol} / \mathrm{L} \mathrm{KOH}$ 溶液中的 $100 \mathrm{~mA}$ 恒流放 电曲线

Fig. 6 Discharge curves of $\mathrm{V}-x \mathrm{~B} / \mathrm{Ni}$ anodes in $6 \mathrm{~mol} / \mathrm{L} \mathrm{KOH}$ solution at constant current of $100 \mathrm{~mA}$ 
表 $1 \mathrm{~V}-x \mathrm{~B} / \mathrm{Ni}$ 型电极组装成空气电池的放电性能参数

Table 1 Discharge property parameters of air cell assembled by $\mathrm{V}-x \mathrm{~B} / \mathrm{Ni}$ anodes

\begin{tabular}{lcccccc}
\hline \multicolumn{1}{c}{ Anodes } & $\begin{array}{c}\text { Voltage } \\
\text { /V }\end{array}$ & $\begin{array}{c}\text { Theoretical capacity/ } \\
\left(\mathrm{mAh} \cdot \mathrm{g}^{-1}\right)\end{array}$ & $\begin{array}{c}\text { Capacity } \\
/ \mathrm{mAh}\end{array}$ & $\begin{array}{c}\text { Specific capacity/ } \\
\left(\mathrm{mAh} \cdot \mathrm{g}^{-1}\right)\end{array}$ & $\begin{array}{c}\text { Percentage of } \\
\text { theoretical capacity } / \%\end{array}$ & $\begin{array}{c}\text { Specific energy/ } \\
\left(\mathrm{Wh} \cdot \mathrm{kg}^{-1}\right)\end{array}$ \\
\hline $\mathrm{V}-(2 / 3) \mathrm{B} / \mathrm{Ni}$ & 0.67 & 3410 & 6129 & 2724 & $79.9 \%$ & 1790 \\
$\mathrm{~V}-\mathrm{B} / \mathrm{Ni}$ & 0.63 & 3573 & 6291 & 2796 & $78.3 \%$ & 1723 \\
$\mathrm{~V}-(3 / 2) \mathrm{B} / \mathrm{Ni}$ & 0.69 & 3735 & 6776 & 3012 & $80.6 \%$ & 2059 \\
$\mathrm{~V}-2 \mathrm{~B} / \mathrm{Ni}$ & 0.72 & 4060 & 7901 & 3512 & $86.5 \%$ & 2504 \\
\hline
\end{tabular}

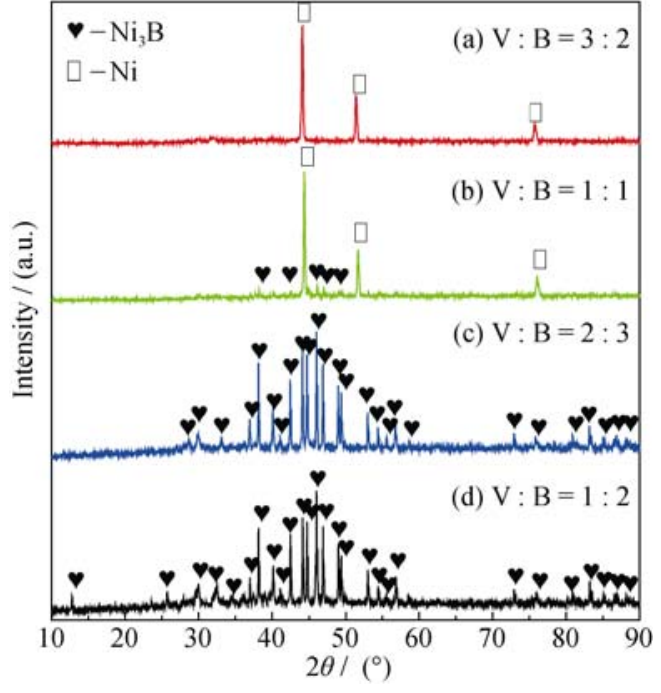

图 $7 \mathrm{~V}-x \mathrm{~B} / \mathrm{Ni}$ 电极片放电后的 XRD 图谱

Fig. 7 XRD patterns of $\mathrm{V}-x \mathrm{~B} / \mathrm{Ni}$ anodes after discharge

极的 XRD 谱图如图 7 所示, 可以看出 V-(2/3)B/Ni 电极放电后为单质 $\mathrm{Ni}$ 相, $\mathrm{V}-\mathrm{B} / \mathrm{Ni}$ 电极放电后由 $\mathrm{Ni}$ 及 $\mathrm{Ni}_{3} \mathrm{~B}$ 组成, 而对于 $\mathrm{B}$ 元素含量较高的 $\mathrm{V}-(3 / 2) \mathrm{B} / \mathrm{Ni}$ 及 $\mathrm{V}-2 \mathrm{~B} / \mathrm{Ni}$ 电极则全部由单一 $\mathrm{Ni}_{3} \mathrm{~B}$ 相组成。相对于 电极放电前，不同成分电极放电后 $\mathrm{V}-x \mathrm{~B}$ 化合物的 衍射峰均全部消失, 表明不同物相的钒嗍化物均在 碱性 $\mathrm{KOH}$ 溶液中反应完全, 释放电能, 其反应产物 全部溶解于电解液中; 而单质 $\mathrm{Ni}$ 及在烧结过程中形 成的 $\mathrm{Ni}_{3} \mathrm{~B}$ 则可以稳定的存在于碱性 $\mathrm{KOH}$ 溶液中, 并不参与电池反应, 仅起到电极导电剂及支撑骨架 作用。

\section{3 结论}

以高温反应合成制备的不同成分配比的钒硼化 物粉体为原料，采用粉末冶金方法制备了空气电极 用多孔负极极片, 研究了不同物相钒嗍化物的放电 输出性能。结果表明:

1) 单质元素混合粉末经过 $1500^{\circ} \mathrm{C}$ 高温处理可 合成钒嗍化物粉末, 当单质元素粉末原子比 $\mathrm{V}: \mathrm{B}=$ $1: 1 、 1: 2$ 时, 可分别制得具有单一物相的 $\mathrm{VB}$ 和 $\mathrm{VB}_{2}$
粉末; 当 $V: B=3: 2$ 时, 合成产物中除了 $V_{3} B_{2}$ 相, 还 含有少量的 $V B$ 相; 当 $V: B=2: 3$ 时, 合成产物则包含 了 $\mathrm{V}_{2} \mathrm{~B}_{3} 、 \mathrm{~V}_{3} \mathrm{~B}_{4}$ 和少量 $\mathrm{VB}_{2}$ 三种物相。

2) 以制备 $\mathrm{V}-x \mathrm{~B}(x=2 / 3 \sim 2)$ 粉末为活性物质, $\mathrm{Ni}$ 为导电剂, $15 \mathrm{wt} \% \mathrm{NH}_{4} \mathrm{HCO}_{3}$ 为造孔剂, 采用粉末冶 金工艺 $900^{\circ} \mathrm{C}$ 无压烧结可制备多孔电极片; 不同活 性物质电极片的孔隙率相差不大，约为 $61 \%$; 电极 烧结制备过程中会产生 $\mathrm{Ni}_{3} \mathrm{~B}$ 新相，随着活性物质中 $\mathrm{B}$ 元素含量升高, 电极 $\mathrm{Ni}_{3} \mathrm{~B}$ 含量显著提升。

3) 随 $\mathrm{B}$ 元素含量的升高, $\mathrm{V}-x \mathrm{~B} / \mathrm{Ni}(x=2 / 3 \sim 2)$ 型 电极的电化学容量逐渐增大, 放电容量也相应提升, 可达到 6129 7901 mAh，其放电比容量在 2724 $3512 \mathrm{mAh} / \mathrm{g}$ 范围内逐渐升高, 电池的库伦效率均可 在 $78 \%$ 以上。

4) 所制备 $\mathrm{V}-2 \mathrm{~B} / \mathrm{Ni}$ 电极的放电输出性能最优, 其比容量达到 $3512 \mathrm{mAh} / \mathrm{g}$, 库伦效率为 $86.5 \%$, 能 量密度达到 $2504 \mathrm{Wh} / \mathrm{kg}$ 。

\section{参考文献:}

[1] LIU Q, WANG Y B, DAI L, et al. Scalable fabrication of nanoporous carbon fiber films as bifunctional catalytic electrodes for flexible $\mathrm{Zn}$-air batteries. Adv. Mater, 2016, 28: 3000-3006.

[2] ZHU M J, YUAN Z S, SANG L, et al. Research progresses of metal/air batteries. Journal of Power Sources, 2012, 36(12): 1953-1955.

[3] NG S H, WANG J Z, WEXLER D, et al. Highly reversible lithium storage in spheroidal carbon-coated silicon nanocomposites as anodes for lithium-ion batteries. Angew. Chem. Int. Ed., 2006, 45(41): 6896-6899.

[4] HE S Y, ZENG J B, JIANG F M. Numerical reconstruction and characterization analysis of microstructure of lithium-ion battery graphite anode. Journal of Inorganic Materials, 2015, 30(9): 906-912.

[5] LEFLER M, STUART J, PARKEY J, et al. Higher capacity, improved conductive matrix $\mathrm{VB}_{2} /$ air batteries. Journal of The Electrochemical Society, 2016, 163(5): A781-A784.

[6] LI Y, DAI H. Recent advances in zinc-air batteries. Chem. Soc. Rev., 2014, 43: 5257-5275. 
[7] Stuart J, HOHENADEL A, LI X G, et al. The net discharge mechanism of the $\mathrm{VB}_{2} /$ air battery. Journal of The Electrochemical Society, 2015, 162(1): A192-A197.

[8] LiCHT S, HETTIGE C, LAU J, et al. Nano-VB 2 synthesis from elemental vanadium and boron: nano- $\mathrm{VB}_{2}$ anode / air batteries. Electrochemical and Solid-State Letters, 2012, 15(1): A12-A14.

[9] WANG Y D, GUANG X Y, PAN M. Mechanochemical synthesis and high-capacity performances of transition-metal borides as aqueous anode materials. Chin. Sci. Bull., 2012, 57(32): 4225-4228.

[10] RHODES C, STUART J, LOPEZ R, et al. Evaluation of properties and performance of nanoscopic materials in vanadium diboride/air batteries. Journal of Power Sources, 2013, 239: 244-252.

[11] STEVEN A, PER O, MICHAEL T K, et al. A novel high power density borohydride-air cell. Journal of Power Sources, 1999, 84(1): 130-133.

[12] WANG Y D, AI X P, YANG H X. A study of metal borides as high capacity anode materials for aqueous primary batteries. Electrochemistry, 2005, 11(1): 16-19.
[13] WANG Y D, GUANG X Y, CAO Y L, et al. Mechanochemical synthesis and electrochemical characterization of $\mathrm{VB}_{x}$ as high capacity anode materialsfor batteries. Journal of Alloys and Compounds, 2010, 501: L12-L14.

[14] LICHT S, WU H, YU X, et al. Renewable highest capacity $\mathrm{VB}_{2} /$ air energy storage. Chem. Commun. (Camb), 2008, 28(28): 3257-3259.

[15] YEH C L, WANG H J. Combustion synthesis of vanadium borides. Journal of Alloys and Compounds, 2011, 509: 3257-3261.

[16] STUART L, GHOSH S, WANG B H, et al. Nanoparticle facilitated charge transfer and voltage of a high capacity $\mathrm{VB}_{2}$ anode. Electrochemical and Solid-State Letters, 2011, 14(6): A83-A85.

[17] STUART J, LOPEZ R, LAU J, et al. Fabrication of $\mathrm{VB}_{2} /$ air cells for electrochemical testing. Journal of Visualized Experiments, 2013, 78: $1-7$.

[18] WEI ZHI-GUO, LU XIN, TONG JIAN-BO, et al. Preparation and discharge performance of porous $\mathrm{VB}_{2}$ anodes for high capacity $\mathrm{VB}_{2}$-air battery. Journal of Inorganic Materials, 2017, 32(2): 122-126. 